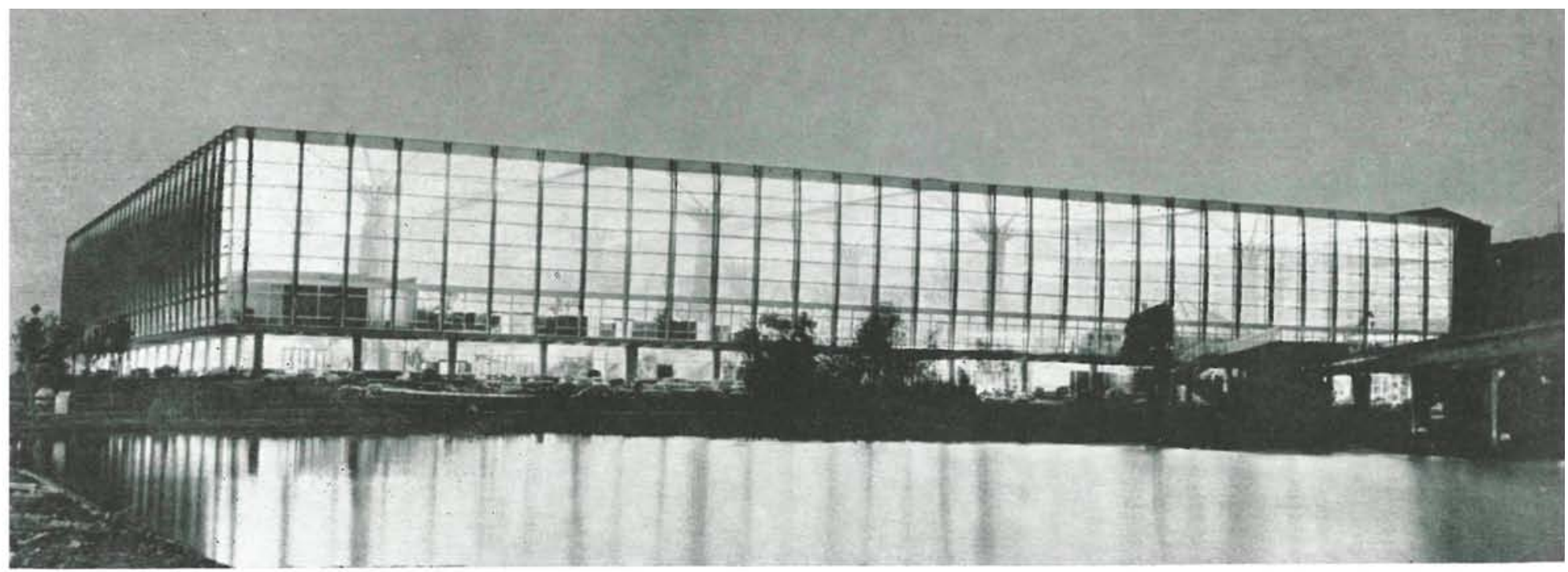

\title{
el palacio del trabajo en Turín
}

PIER LUIGI NERVI y ANTONIO NERVI, ingenieros

$504 \cdot 3$

Con la denominación de Palacio del Trabajo se ha construído en Turín (Italia) un magnífico edificio, rodeado de anexos e instalaciones, que se ha destinado, con fines inmediatos, a una exposición. La parte central de ésta se reserva a Italia y la circundante al extranjero y, con fines mediatos, a otras actividades de carácter indefinido.

El estudio ejecutivo de la estructura metálica ha sido llevado a cabo por el ingeniero Gino Covre, cuya competencia y experiencia están sobradamente probadas.

La cubierta de este edificio está constituída por 16 soportes, terminados en su parte superior por formas metálicas, cuadradas, de $40 \mathrm{~m}$ de lado y situadas a $20 \mathrm{~m}$ de altura respecto al suelo. El fuste de estos soportes, de hormigón armado, tiene una sección en forma de cruz en su base y circular en la parte superior.

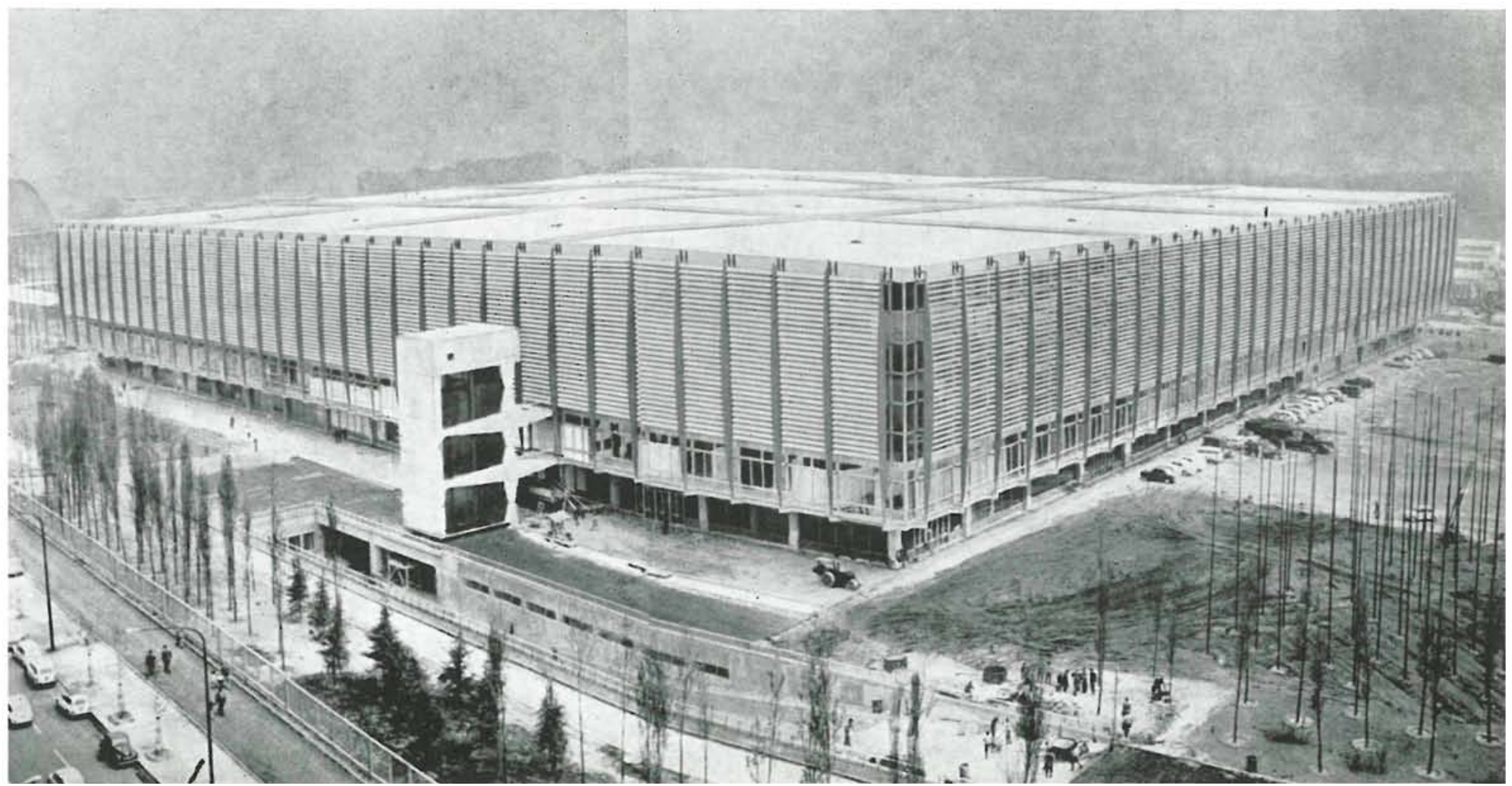




\section{planta}

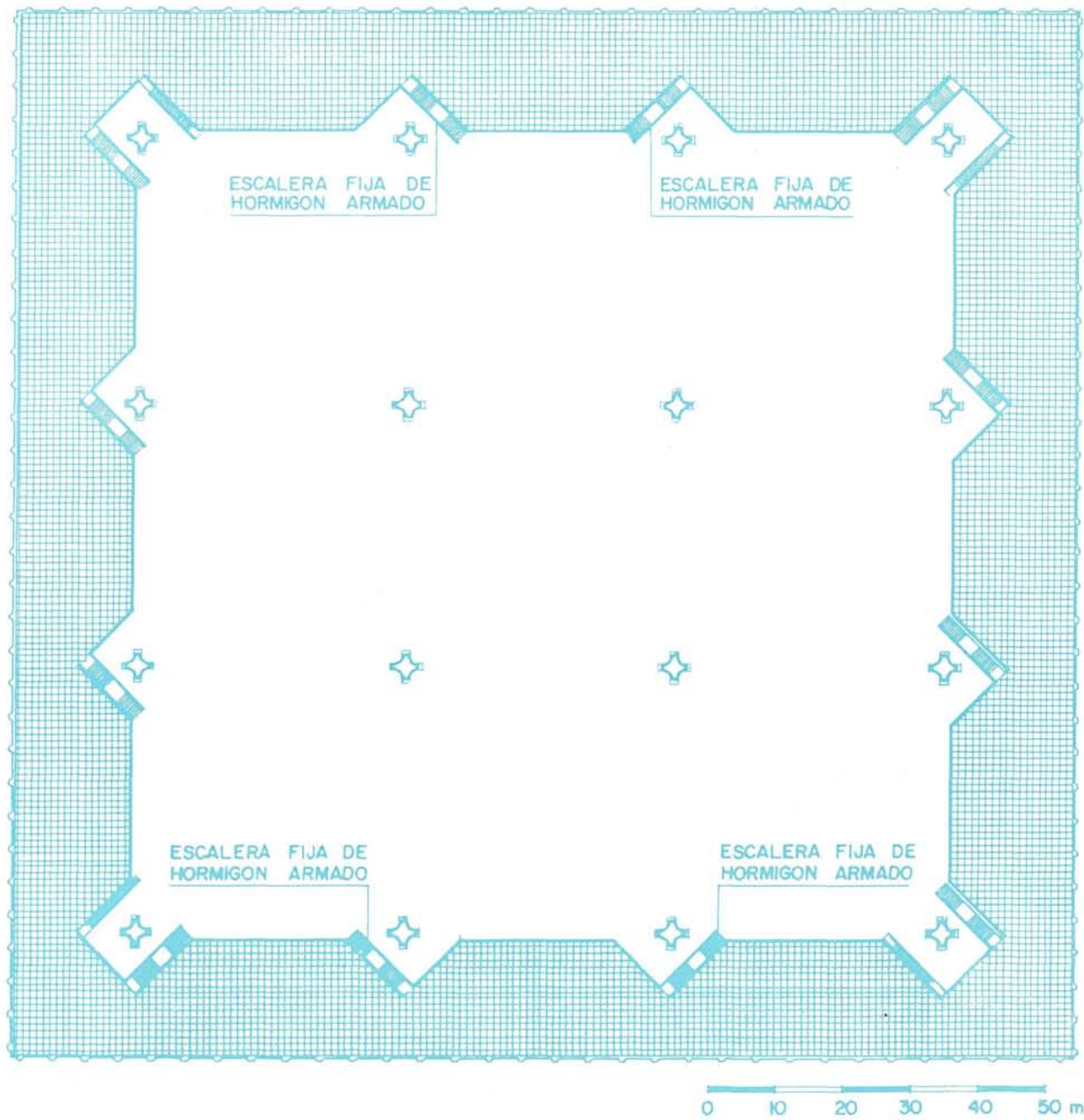

El proyecto de los soportes, dada la altura inusitada de éstos y su carácter particular en lo que a la superficie externa se refiere, ha creado un problema cuya solución ha exigido de cierto empeño. En principio, se necesitaba un encofrado que respondiese a las singulares características de la superficie externa. Este encofrado debía ser suficientemente robusto para resistir a la presión estática que crea el hormigonado y, además, debía permitir su reempleo sucesivo con objeto de lograr una regularidad en todos los soportes.

El encofrado se subdividió en seis trozos, cada uno de los cuales se componía de cuatro piezas. La parte resistente de estos trozos se compone de perfiles metálicos laminados que se unen entre sí mediante pernos. Los paños del encofrado están formados por una doble capa de tabla. En la capa interna las tablas, en sentido vertical y de longitud variable, se unen entre ellas, constituyendo una especie de duelas.

La subdivisión en seis partes ha sido de gran provecho, bien por haberse obtenido elementos relativamente ligeros, bien por permitir un desencofrado muy fácil. El ciclo del hormigonado de cada uno de estos soportes ha absorbido un período de tiempo de diez días.

Otro problema que ha sido necesario afrontar obedece a la necesidad de un forjado, de $7.000 \mathrm{~m}^{2}$, situado en la planta baja, y otro, de $10.000 \mathrm{~m}^{2}$, que se halla en la cota $231,40 \mathrm{~m}$. El tiempo disponible 
para el hormigonado de estos forjados era muy breve y ligado, en lo que a ejecución se refiere, con la construcción de la cubierta metálica. El forjado de planta baja debía preceder a la colocación de la cubierta, mientras que el de la cota 231,40 debía seguir inmediatamente.

El forjado de la planta baja, previsto para una sobrecarga de $2.000 \mathrm{~kg} / \mathrm{m}^{2}$, se compone de un reticulado, de $10 \times 10 \mathrm{~m}$, que se ha formado con vigas prefabricadas, de $10 \mathrm{~m}$ de luz, que se han espaciado a $1,66 \mathrm{~m}$ sobre las vigas principales hormigonadas en la obra. Sobre las vigas secundarias o viguetas van las losas prefabricadas, de $10 \mathrm{~cm}$ de espesor. Estas viguetas, de $3.000 \mathrm{~kg}$ de peso, se han colocado en obra con grúas. Las losas, de $700 \mathrm{~kg}$ cada una, se han colocado con grúa tipo "Derridc".

El forjado perimetral, previsto para la cota 231,40 , se ha calculado para una sobrecarga de $400 \mathrm{~kg} / \mathrm{m}^{2}$ y con sus dos partes laterales constituyendo ménsula de $4 \mathrm{~m}$ de vuelo.

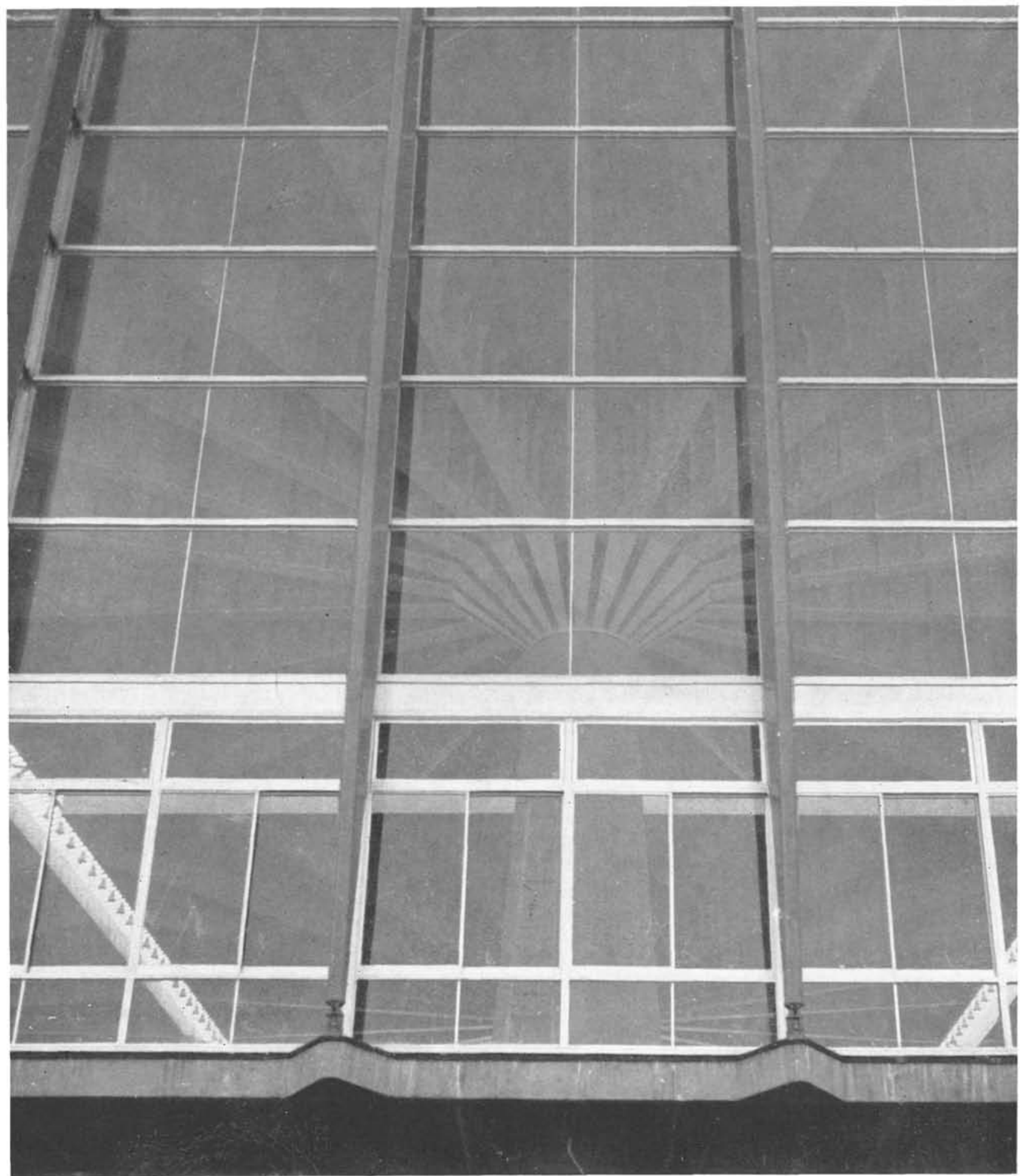



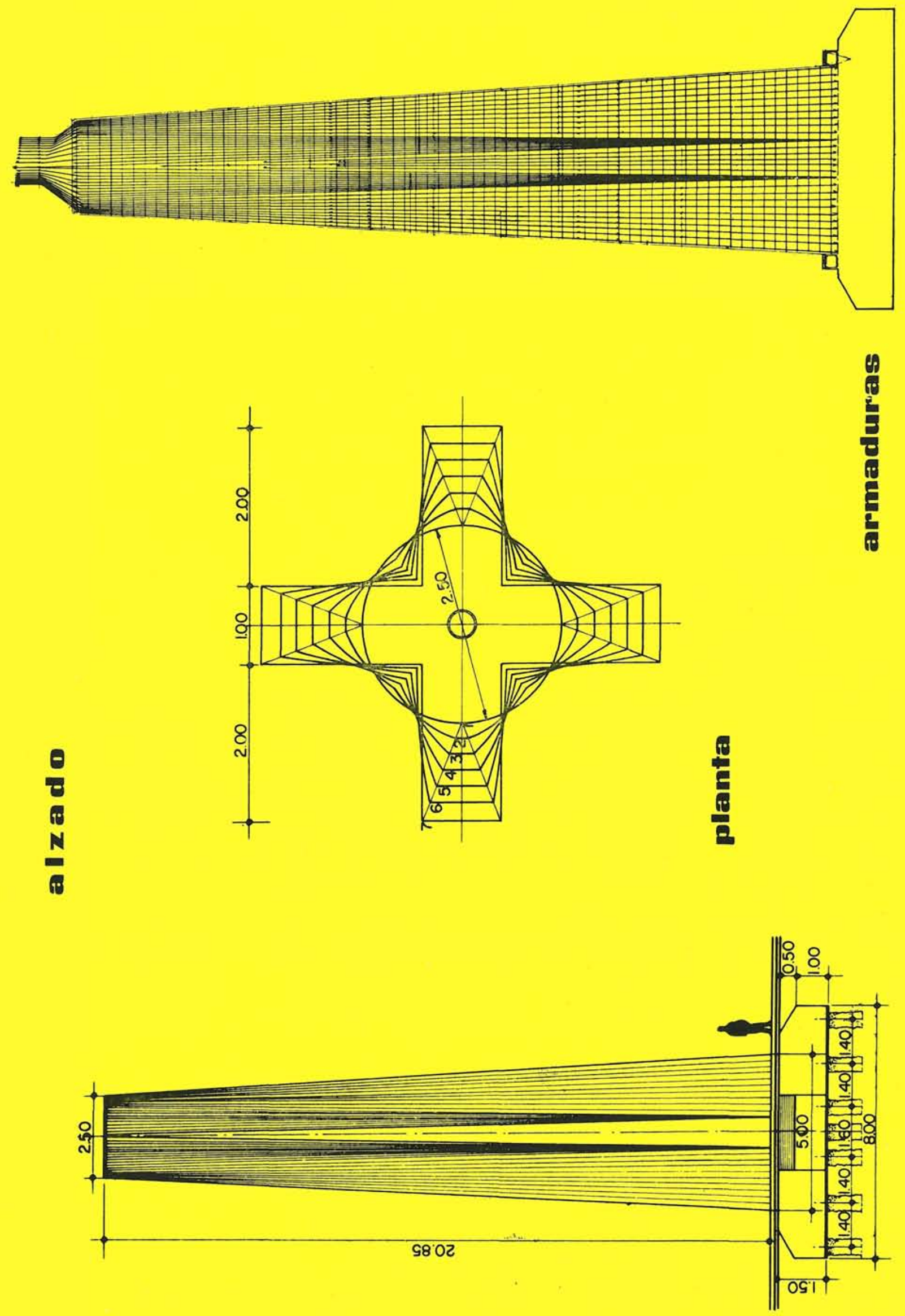

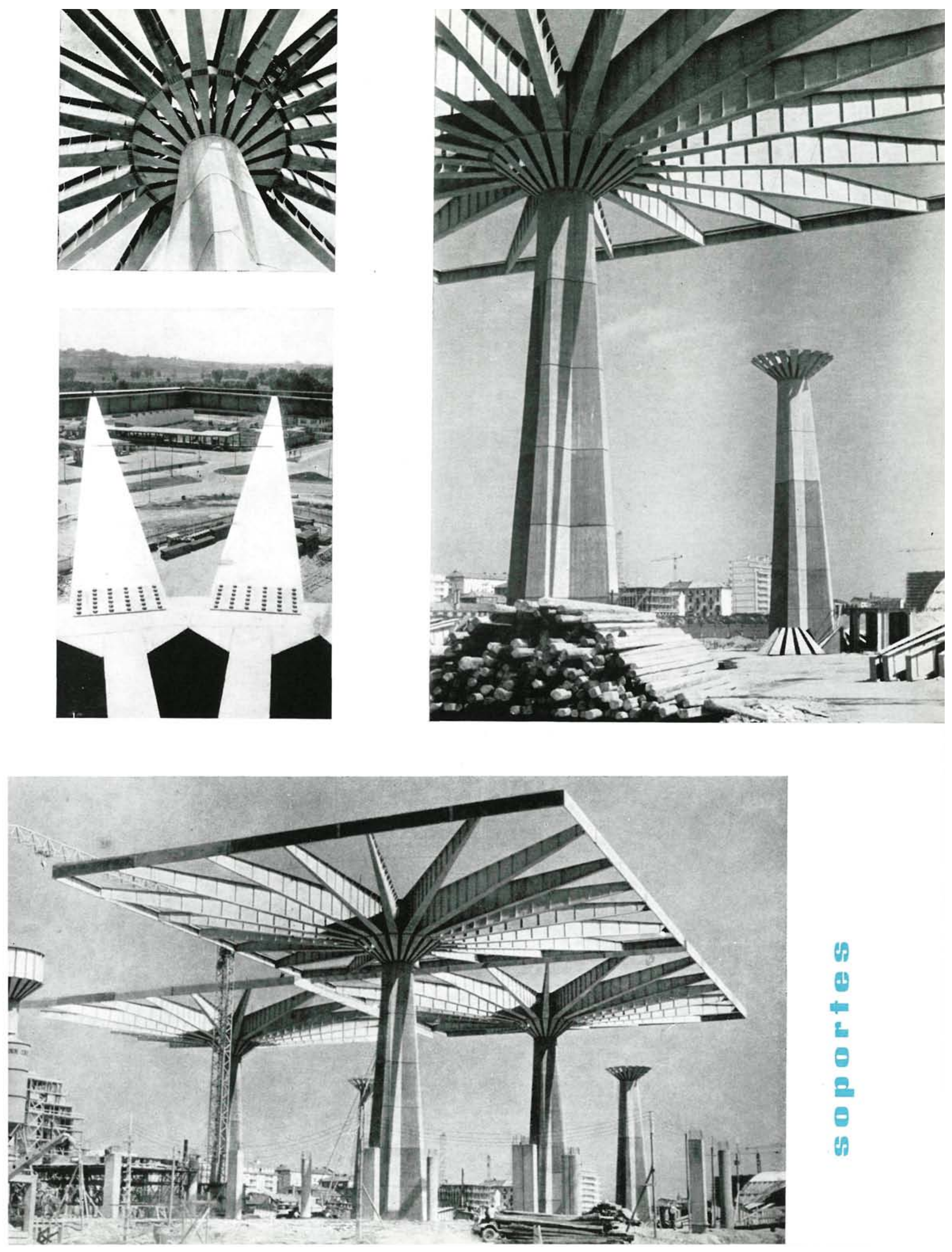
entroplantat

Para la construcción de este último forjado se han adoptado encofrados especiales con objeto de conseguir un trazado curvilíneo artístico en la parte central.

Estos encofrados se han montado sobre entramados móviles que se podrán trasladar, después de desencofrar, a la parte adyacente, donde se le ponía en posición y se continuaba hormigonando. En este sistema constructivo las estructuras resultan completamente lisas y terminadas en su primera fase bruta, $y$ no requieren otro tratamiento.

Para el hormigonado se ha instalado una central hormigonera fija en la parte frontal de la fachada sur del edificio.

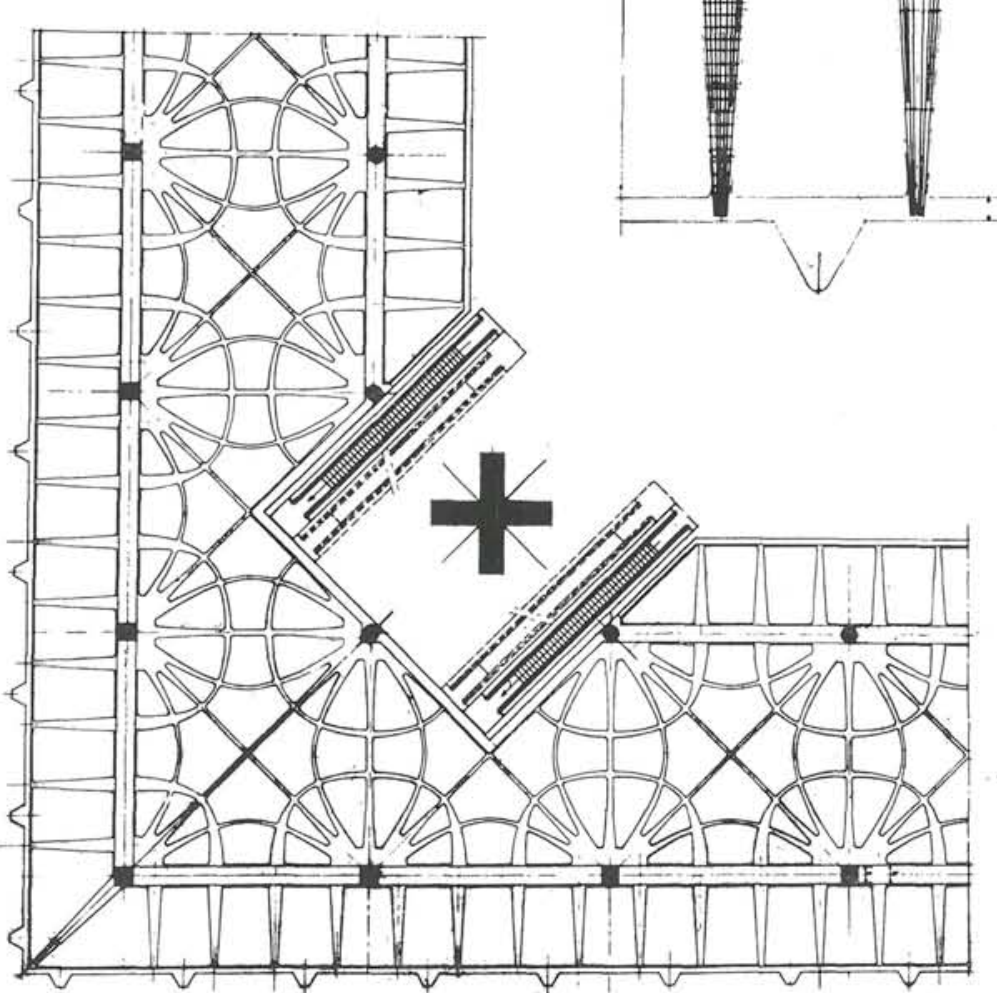

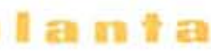
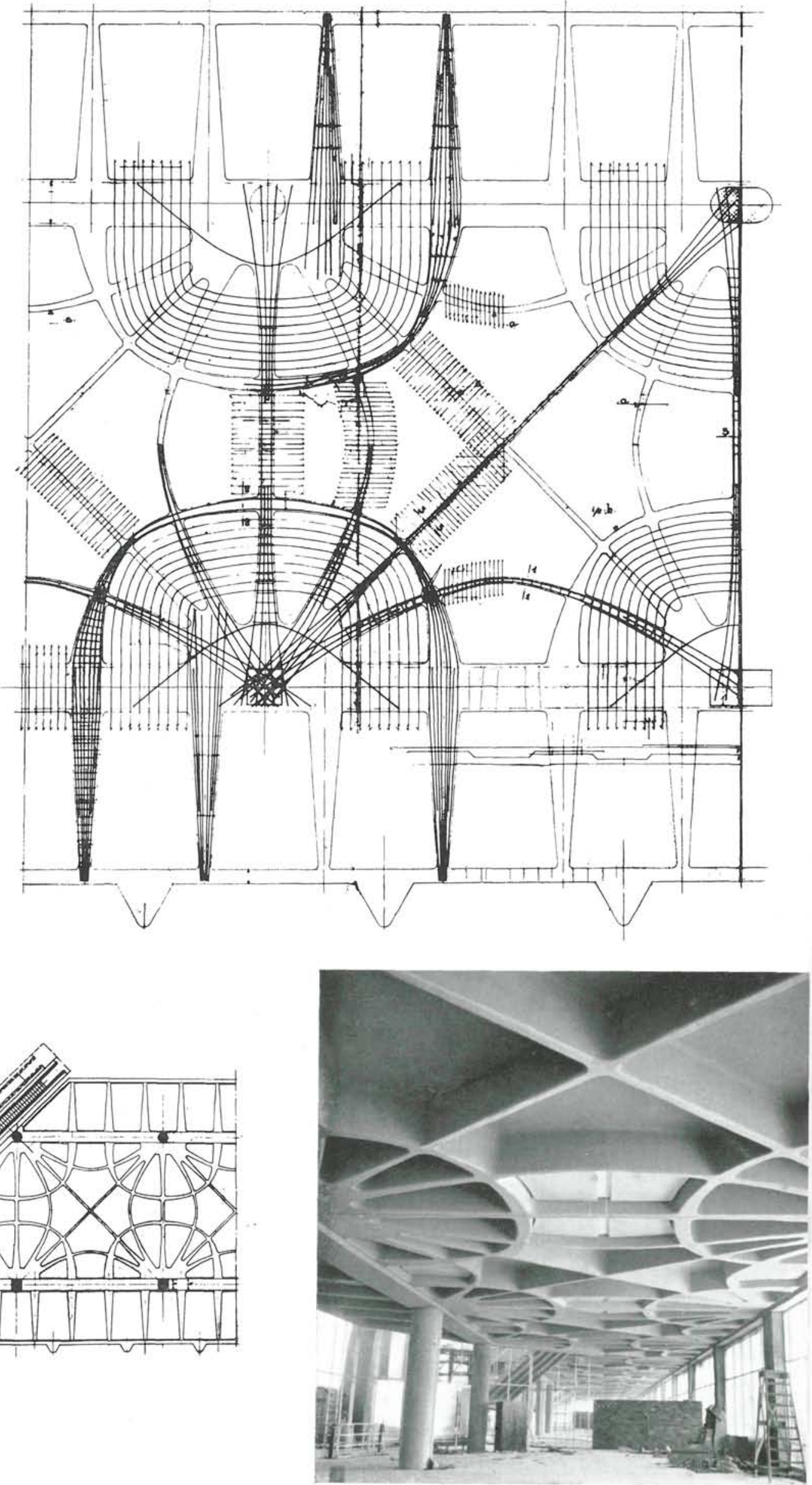

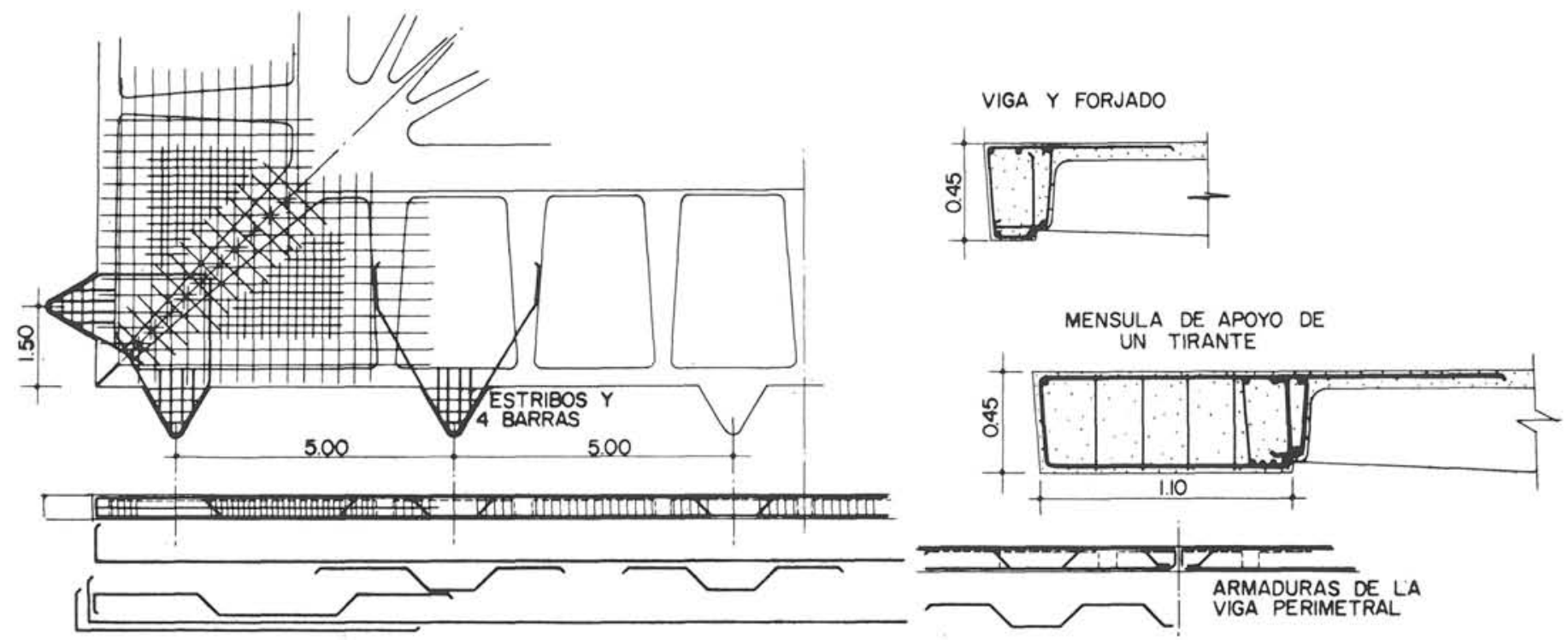

El hormigón se transportaba a los soportes por medio de una bomba de aire comprimido que lo dejaba en los cazos de las grúas para ser elevado hasta los encofrados. Para atender a estos transportes se instalaron tres grúas, una en la parte central de la obra y otras dos, una en cada fila externa de soportes, con objeto de cubrir toda la zona de trabajo con sus respectivos radios de acción.

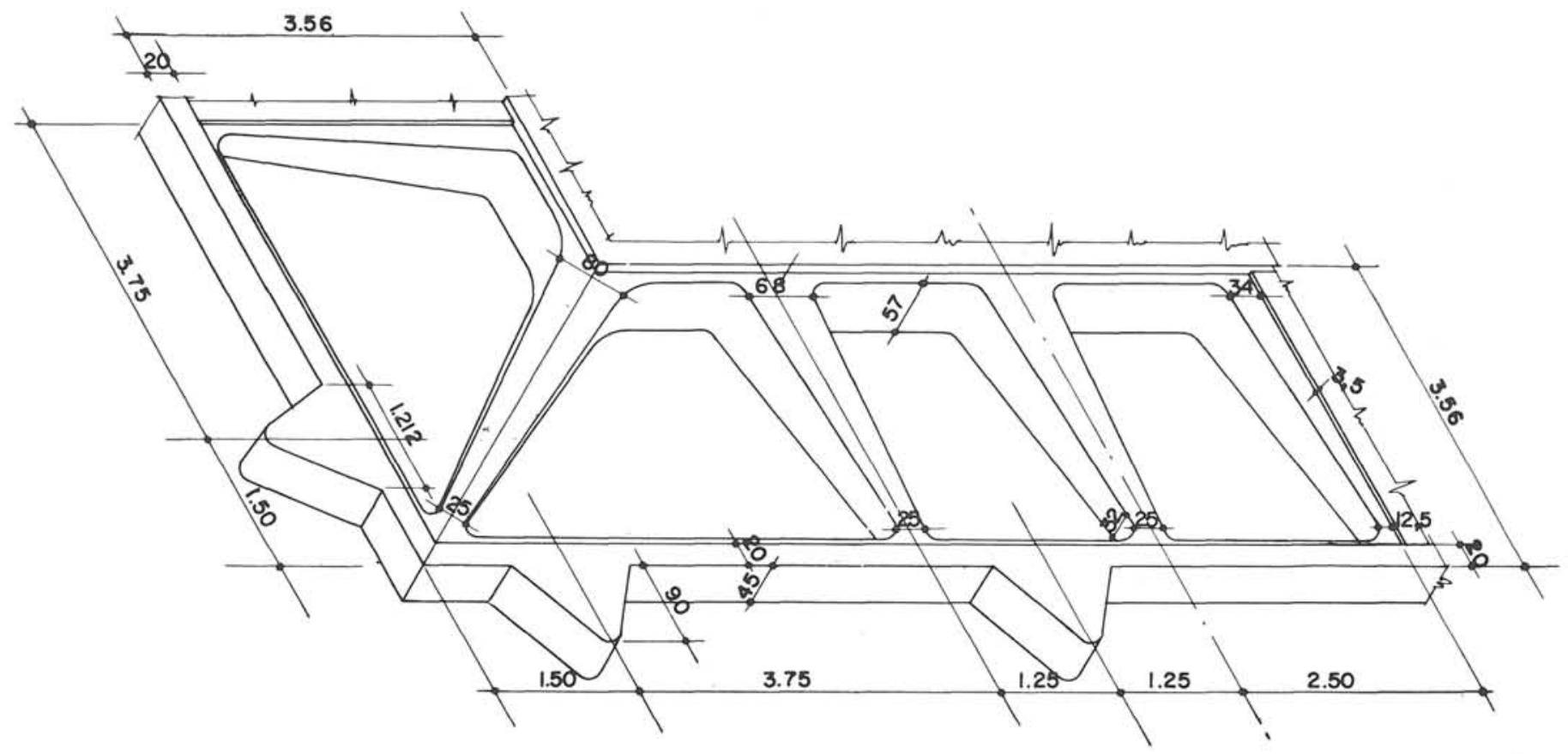



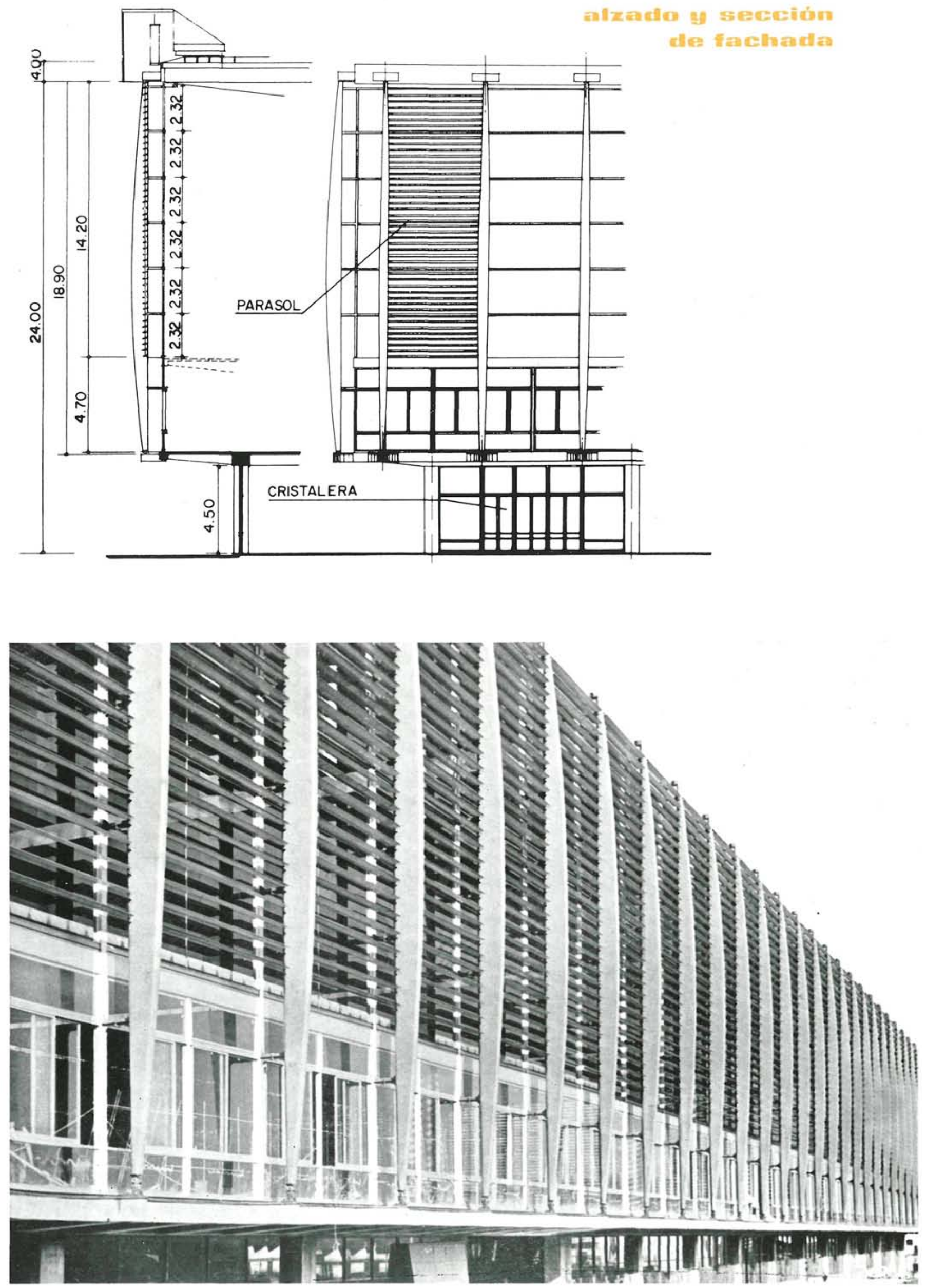


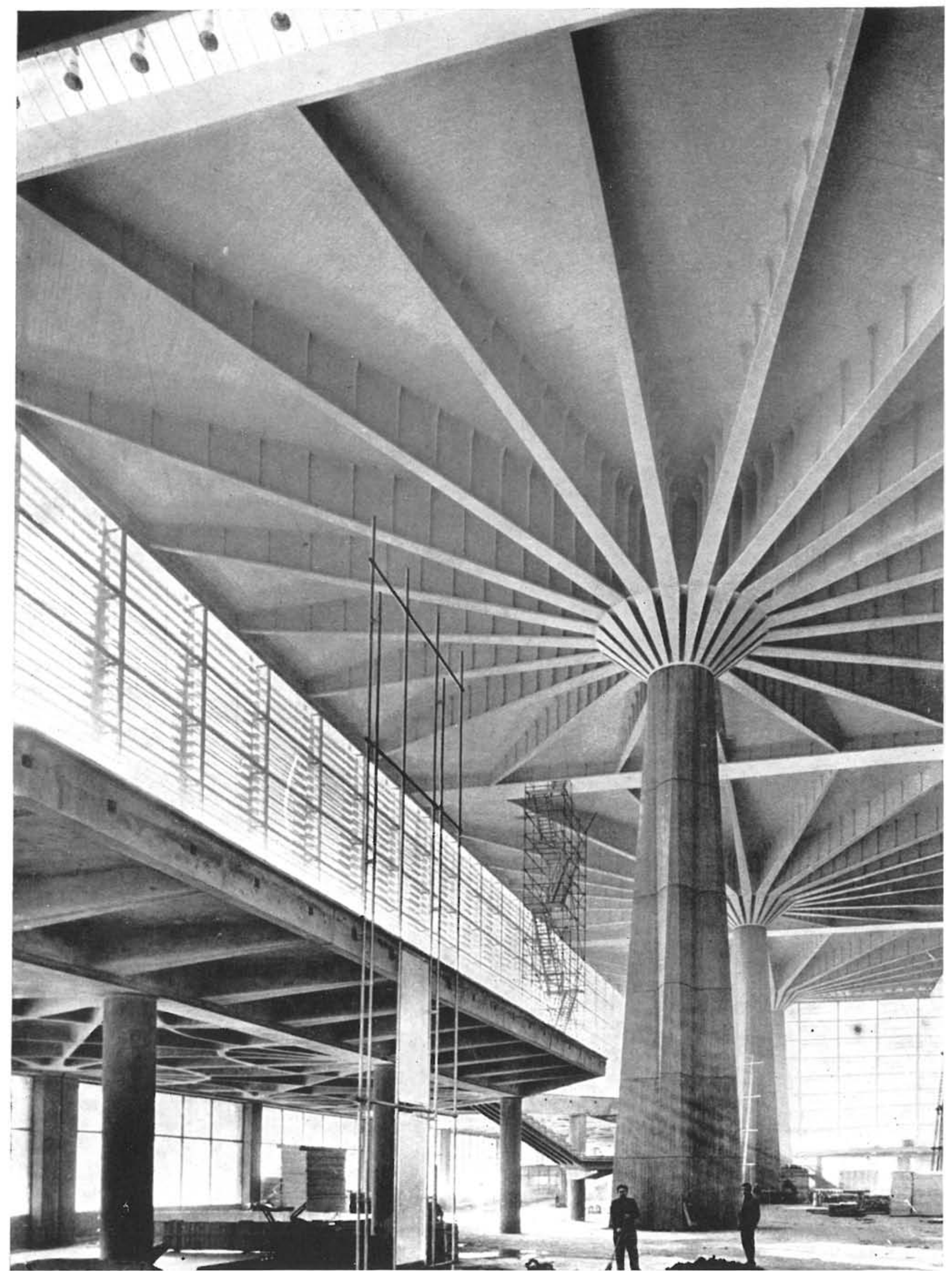




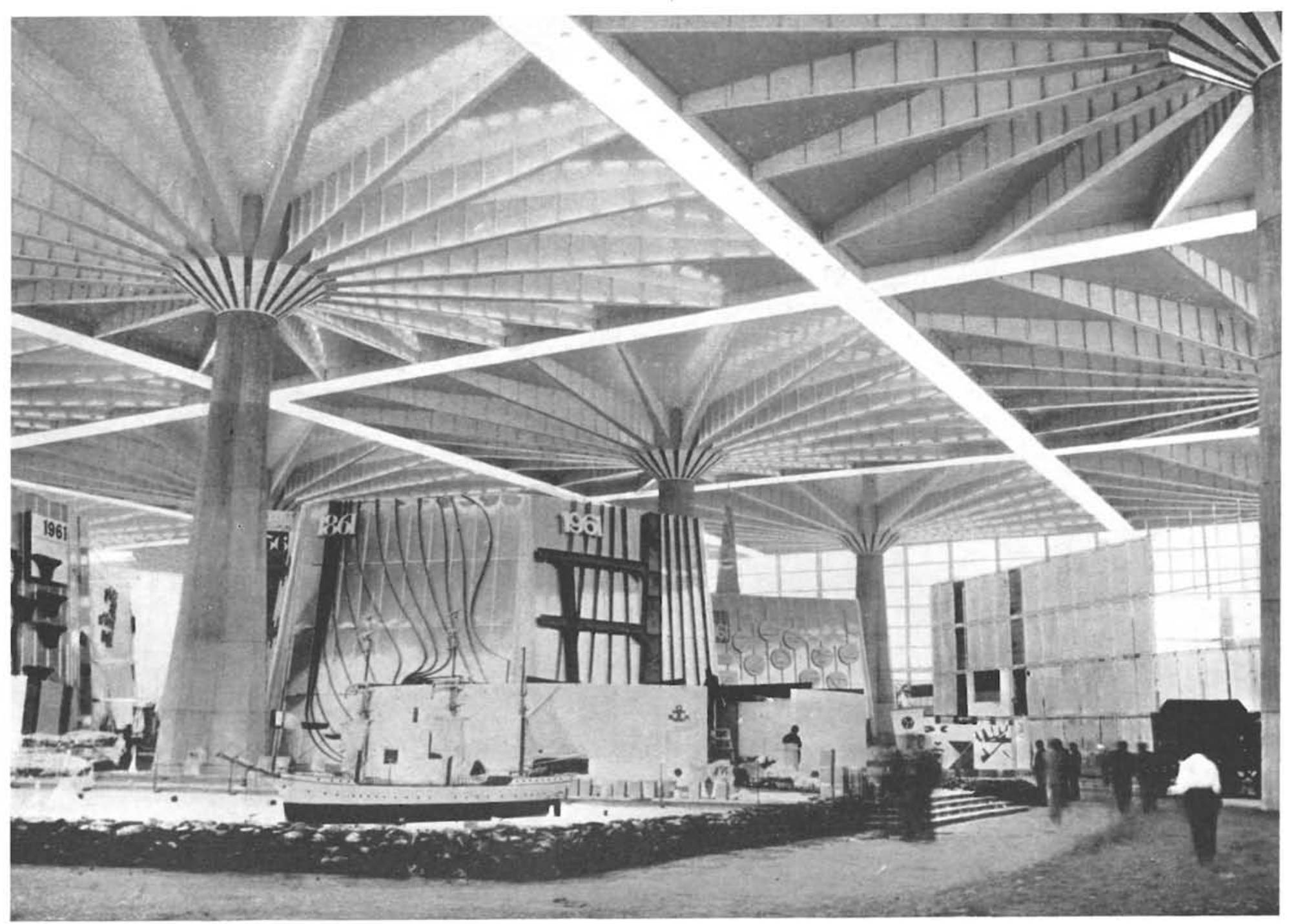

La colocación y montaje del entramado metálico que constituye la cubierta, parcialmente prefabricada en taller, se ha sujetado a las siguientes fases: formación del capitel; colocación del tambor cilíndrico base de apoyo; montaje de las piezas radiales, dos a dos opuestas radialmente, y, finalmente, cubrir con chapa acanalada el entramado metálico de piezas radiales.

Terminado el montaje de la cubierta se procedió a colocar los tirantes exteriores, perimetrales, de fachada, que fijan la cubierta contra los efectos del viento en forma de subpresión y que tienden a levantarla. Para el montaje del entramado metálico de cubierta se han utilizado grúas de gran pluma y alcance en altura.

La implantación de la obra se inició en enero de 1960; los trabajos empezaron en febrero de 1960; la obra se terminó el 28 de febrero de 1961, y, seguidamente, empezó la instalación de la exposición y se inauguró el 6 de mayo de 1961 . 